\title{
Chloride-Induced Highly Active Catalyst for Methyl Esterification of Alcohols
}

\author{
Chengming Zhang*, Yongzhao Wang, Yongxiang Zhao \\ Engineering Research Center of Ministry of Education for Fine Chemicals, Shanxi University, China
}

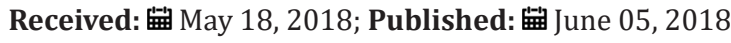

*Corresponding author: Chengming Zhang, Engineering Research Center of Ministry of Education for Fine Chemicals, School of Chemistry and Chemical Engineering, Shanxi University, Taiyuan 03006, China, Tel: +86 0351-7010588; Email: zhangchm@sxu.edu.cn

\begin{abstract}
In this work, a series of active $\mathrm{Au} / \mathrm{NiOx}$ catalysts were successful to prepare by tracing the concentrations of chloride in the re-dispersed aqueous solutions. By characterizations, we found that the appropriate amount of residual chloride in Au catalyst would induce $\mathrm{Au}$ nanoparticles (Au NPs) to locate on the edges of NiOx particles, which resulted in the active Au/NiOx-9 sample. Fine control of chloride in the aqueous solution provides a new perspective to push for addressing the controllable preparation of active heterogeneous catalysts.
\end{abstract}

Keywords: Au catalyst; Preparation; Chloride; Esterification

\section{Introduction}

In recent decades, Au catalysts have received growing attentions and been widely applied in many important research fields [1], since good performance of Au catalysts was discovered [2]. However, the controllable preparation of highly active heterogeneous catalysts is still a longstanding challenge till now, especially Au catalysts. Many efforts have been devoted to this problem. The active site, structure and the quantum size effect of Au catalyst [3], active oxygen species of the support [4], suitable reducible oxide supports [5],and so on, have been extensively studied. Additionally, catalyst precursors, bases, $\mathrm{pH}$ value, aging time, and calcinations temperature are also crucial conditions $[2,6]$. Nevertheless, the controllable preparation of highly active Au catalyst is still difficult to realize even strictly following all above conditions. Chloride (usually as $\mathrm{Cl}$-) is generally regarded as a poison for Au catalyst, Because of strong interaction of chloride and $\mathrm{Au}$. We realized the reproducible preparation of $\mathrm{Au} / \mathrm{Fe}_{2} \mathrm{O}_{3}$ catalyst for $\mathrm{CO}$ oxidation [7]. It is meaningful to explore whether this method can be applied to other catalysts and reactions or not. In this work, Methyl esterification of alcohols was chosen as model reaction. The controllable preparation of highly active $\mathrm{Au} /$ NiOx catalyst was realized by tracing the concentrations of chloride in the re-dispersed aqueous solutions.

\section{Experimental Details}

\section{Au/NiOx catalyst preparation}

$20 \mathrm{ml} \mathrm{Ni}\left(\mathrm{NO}_{3}\right)_{3} 6 \mathrm{H}_{2} \mathrm{O}(0.011 \mathrm{M})$ and $1.05 \mathrm{ml} \mathrm{HAuCl}_{4}(0.24 \mathrm{M})$ were mixed together and were drop wise added into $60 \mathrm{ml} \mathrm{Na}_{2} \mathrm{CO}_{3}$ solution $(0.31 \mathrm{M})$ under vigorous stirring in $3 \mathrm{~h}$. The turbid liquid was divided into four sections and separation by centrifugation. Each section of the recovered precipitate was re-dispersed in different amount of deionised water and ultrasonically washed for $1 \mathrm{~h}$. The chloride concentration in the re-dispersed aqueous solution of each section was determined by CHI660D electrochemical workstation. Then, the solid was separated by centrifugation, dried at $80 \mathrm{o} \mathrm{C}$ for $3 \mathrm{~h}$ and calcined at $350 \mathrm{oC}$ for $0.5 \mathrm{~h}$ to produce the catalyst sample, which was denoted as $\mathrm{Au} / \mathrm{NiOX}-\mathrm{X}$, in which $\mathrm{X}$ suggested the chloride concentration in ppm.

\section{Catalyst activity test}

$1 \mathrm{mmol}$ benzyl alcohol, $30 \mathrm{mg}$ catalyst and $2 \mathrm{ml}$ methanol were added into a glass tube. And then it was exchanged with oxygen and reacted at $60 \mathrm{o} \mathrm{C}$ ( 1 atom, 02 balloon). After reaction, it was cooled to room temperature. Biphenyl was used as internal standard and a certain amount of ethanol were added into the reaction mixture up to $10 \mathrm{~mL}$ for quantitative analysis by GC-FID (Agilent 7890A).

\section{Results and Discussion}

The catalytic activities of $15 \mathrm{Au} / \mathrm{NiOx}$ samples, which were prepared from the re-dispersed aqueous solutions with chloride concentrations in the range of 2 to $108 \mathrm{ppm}$, for esterification of benzyl alcohol were studied. According to the results shown in Figure 1, catalytic activity of $\mathrm{Au} / \mathrm{NiOx}$ varied with the changing of chloride concentration. The yields of methyl benzoate were lower than $21 \%$ if the catalysts were prepared from aqueous solutions 
containing $>22 \mathrm{ppm}$ chloride. More active catalysts were produced when the chloride concentrations were going down. The $\mathrm{Au} /$ $\mathrm{NiOx}$ catalysts with the highest catalytic activity were prepared from aqueous solutions containing 8-13ppm chloride, the yield of methyl benzoate of catalyst $\mathrm{Au} / \mathrm{NiOx}-9$ was $>99 \%$. Surprisingly, the catalysts turned less active again when the chloride concentrations were < 8ppm. Typically, the yield of methyl benzoate was $20 \%$ with catalyst $\mathrm{Au} / \mathrm{NiOx}-3$.

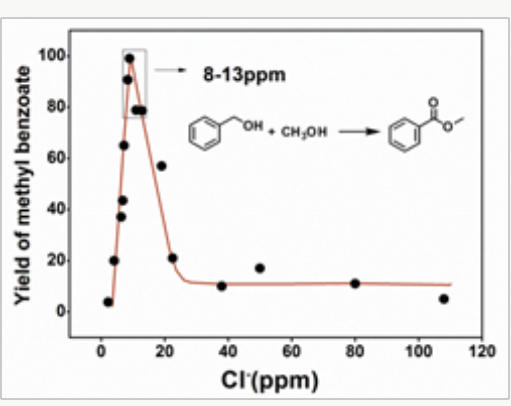

Figure 1: The yield of methyl benzoatevs the chlorine concentration of the aqueous solution from which the catalyst samples were prepared.
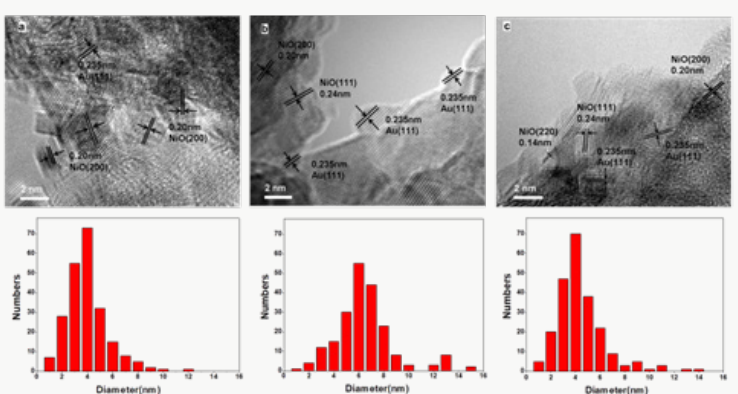

Figure 2: HR-TEM (left) images and size distributions (right) of $\mathrm{Au} / \mathrm{NiOx}-22$ (a), $\mathrm{Au} / \mathrm{NiOx}-9$ (c), and $\mathrm{Au} / \mathrm{NiOx}-$ 3(e).

TEM measurement results of $\mathrm{Au} / \mathrm{NiOx}$ are shown in Figure 2. Their TEM images were similar and seemed amorphous. For the sample of $\mathrm{Au} / \mathrm{NiOx}-22$, the lattice of gold could be observed and wrapped in NiOx particle. For active $\mathrm{Au} / \mathrm{NiOx}-9$, the most of $\mathrm{Au}$ NPs connected with the edges of NiOx particles or the junctions of several NiOx particles [8]. In consideration of the best catalytic performance of this sample, this observation strongly supported the former results about active site in Au catalyst, i.e. the interface between $\mathrm{Au}$ and iron oxide [3]. It suggested that the appropriate amount of chloride might act as the linkage between Au NPs and the edges of $\mathrm{NiOx}$ particles to gain the active $\mathrm{Au}$ catalyst, For $\mathrm{Au} /$ NiOx-22 and $\mathrm{Au} / \mathrm{NiOx}-3$, too much or less chloride was presented, the interaction of $\mathrm{Au}$ NPs and NiOx like Au/NiOx-9 decreased significantly. Accordingly, the catalytic activity lost sharply. By metering more than 150Au NPs, the mean diameters of Au NPs in samples $\mathrm{Au} / \mathrm{NiOx}-3, \mathrm{Au} / \mathrm{NiOx}-9$ and $\mathrm{Au} / \mathrm{NiOx}-22$ were 4.1, 3.8 and $6.6 \mathrm{~nm}$ with $1.91,1.84$ and 3.06 standard deviations. The size distributions of $\mathrm{Au}$ NPs in $\mathrm{Au} / \mathrm{NiOx}-3$ and $\mathrm{Au} / \mathrm{NiOx}-9$ samples were extremely similar. The marked difference of catalytic activities of these two catalysts did not come from the size effect of Au particles, but the contact way of Au NPs and NiOx supports.

At present, there is still not sufficient evidence to explain the real role of chloride in the formation of Au catalysts. However, according to the known evidence, we can make some reasonable conjectures. Firstly, as $\mathrm{pH}$ value of the mother aqueous solution rises, chlorine in chloroauric acid is substituted by the hydroxyl. $\mathrm{Au}-\mathrm{Cl}$ bond breaks and then small Au NPs form. Finally, chloride is adsorbed on the support NiOx as well as Au NPs. Due to the stronger interaction of chlorideon the edges than on planes of NiOx crystallites, after the ultrasonication and washing operations, chloride located on the edges of NiOx crystallites remains. As shown in Figure 3, it is this kind of residual chloride that induces Au NPs to anchor on the edges of NiOx crystallites.

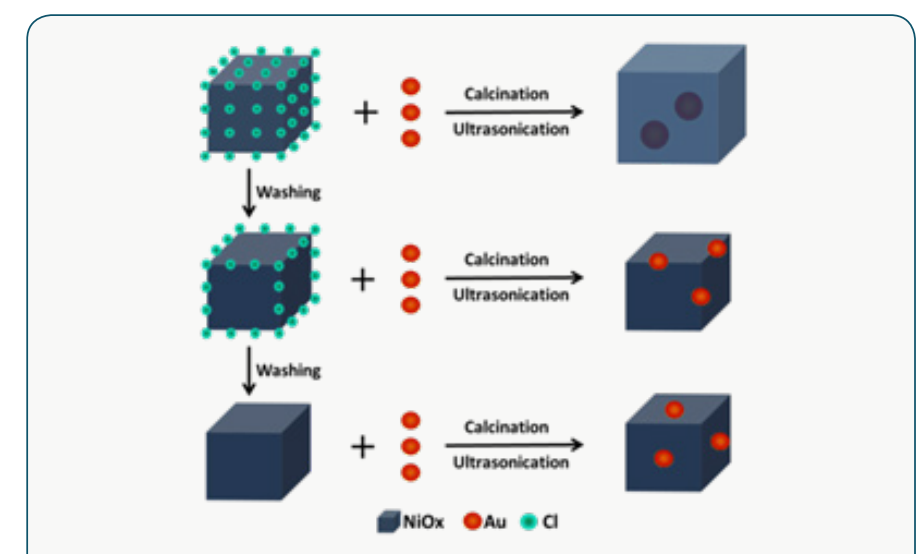

Figure 3: The simple scheme of $\mathrm{Au} / \mathrm{NiOx}$ catalysts.

\section{Conclusion}

In summary, by tracing the chloride concentrations in the re-dispersed aqueous solution, we successfully prepared active $\mathrm{Au} / \mathrm{NiOx}$ catalyst for catalytic methyl esterification of alcohols. If the chloride concentration was not in the range of $8-13 \mathrm{ppm}$, the catalytic activity dropped dramatically. These results indicated that the presence of appropriate amounts of residual chloride was beneficial to obtain highly active heterogeneous catalysts. This work can offer a new perspective to realize the controllable preparation of active heterogeneous catalysts.

\section{References}

1. R Ciriminna, E Falletta, Cristina Della Pina, JH Teles, M Pagliaro (2016) Industrial Applications of Gold Catalysis. Angew Chem Int 55(46): 2-10.

2. M Haruta, N Yamada, T Kobayashi, S Iijima (1989) Gold catalysts prepared by coprecipitation for low-temperature oxidation of hydrogen and of carbon-monoxide. J Catal 115(2): 301-309.

3. GC Bond, DT Thompson (2000) Gold-catalysed oxidation of carbon monoxide. Gold Bull 33(2): 41-51.

4. T Fujitani, I Nakamura (2011) Mechanism and active sites of the oxidation of $\mathrm{CO}$ over $\mathrm{Au} / \mathrm{TiO}_{2}$. Angew Chem Int 50(43): 10144-10147.

5. X Xu, Q Fu, X Guo, X Bao (2013) A Highly Active "NiO-on-Au" Surface Architecture for CO Oxidation. ACS Catal 3(8): 1810-1818. 
6. Hugon, N El Kolli, C Louis (2010) Advances in the preparation of supported gold catalysts: Mechanism of deposition, simplification of the procedures and relevance of the elimination of chlorine. J Catal 274(2): 239-250.

7. Zhang, L Liu, X Cui, L Zheng, Y Deng, F Shi (2013) Chlorine as an indicator in the controllable preparation of active nano-gold catalyst. Sci Rep 3: 1503-1507.
8. H Tang, F Liu, J Wei, B Qiao, K Zhao, et al. (2016) Ultrastable Hydroxyapatite/Titanium-Dioxide-Supported Gold Nanocatalyst with Strong Metal-Support Interaction for Carbon Monoxide Oxidation. Angew Chem Int 55(36): 10606-10611.

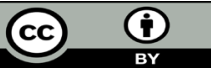

This work is licensed under Creative Commons Attribution 4.0 License

To Submit Your Article Click Here: Submit Article

DOI: $10.32474 /$ AOICS.2018.03.000154

\section{AOICS}

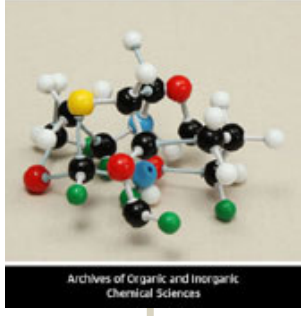

Archives of Organic and Inorganic Chemical Sciences

Assets of Publishing with us

- Global archiving of articles

- Immediate, unrestricted online access

- Rigorous Peer Review Process

- Authors Retain Copyrights

- Unique DOI for all articles 